\title{
OPEN DISTANCE LEARNING AND IMMERSIVE TECHNOLOGIES: A LITERATURE ANALYSIS
}

\author{
Afika Ntaba and Mmaki Jantjies \\ University of the Western Cape, South Africa
}

\begin{abstract}
Open and distance learning (ODL) education provides an opportunity for prospective students who require flexibility in education enabling learning without traditional face to face lecture sessions. Previous literature indicated that there has been a growing curiosity amongst educators, researchers, and pedagogues on employing modern visualization technologies to enrich current educational experiences for students who do not attend face to face lessons. This study aims to explore how new immersive technology can be used to enhance the experience of distance learning. Using a systematic literature review, findings were presented in the form of a thematic discussion looking at journal articles between the year 2000 to October 2018. Following a review of 40 articles which were included in the qualitative synthesis, this study investigated the challenges experienced in open distance learning experience, in an attempt to form the basis of interlinking the use of Virtual and Augmented Reality (AR) technologies to enhance the distance learning experience. Findings revealed ODL presently employs various Information and Communication Tools (ICT) which are comprised of technological resources that assist the facilitation of lecturer and student interaction. However, these ICTs do not fully assist in enhancing the DL experience. Results from the review found that the adoption of Augmented and Virtual Reality (VR) in higher education contributed to learner engagement and enhanced learning outcomes. Moreover, literature revealed that immersive learning is best utilized as a complement to traditional learning as opposed to a replacement.
\end{abstract}

\section{KEYWORDS}

Immersive Technology, Virtual Reality, Augmented Reality, Distance Learning

\section{INTRODUCTION}

Al-Arimi (2014) defines distance learning (DL) as a discipline in education that is centered on the pedagogy, technology and teaching design methodology that is effective in providing education to learners. UNISA (2018) which is South Africa's largest long-distance educational institutions, articulates that traditionally distance education could be related to correspondence courses, where the learning institution and the learner would make use of postal services as a means of exchanging learning material as well as communication-related to the process. Baukal (2010) states that DL can be asynchronous, where the learner engages with the academic material at a time suitable to them (e.g. viewing videotaped lectures). DL can also be synchronous, where the learner is engaging with a teacher in real-time through technology such as teleconferencing and webinars.

It is crucial to investigate why individuals enroll in higher education distance learning institutions. This objective will form the basis of understanding the student experience discussed in this paper. Simpson and Anderson (2012) report that the first distance learners were primarily composed of women and the working class motivated by a lack of adequate services from formal institutions and also having to work in order to pay for fees. The reasons for enrolling in distance learning has since evolved over the years. Rodrigues et al. (2014) states that individuals that enroll in distance learning seek to adopt an educational framework that is not restricted to a physical classroom, is not costly, and most importantly, has a high level of flexibility. Distance learners seek to make better use of their time, have geographic independence and also often require a flexible schedule (Rodrigues et al., 2014).

Leszczyński et al. (2017) details the benefits of DL as time saving and providing access to an extensive variety of learners, flexible learning hours, the prospect of modifying academic content to the individual learner, and decreased education cost in the long run. Markova et al. (2017) found that the primary reason that had influenced student's decision to choose DL to be the prospect of being able to combine their studies and 
employment, followed by the opportunity to study from home, and lastly the flexibility of "school hours". DL is, therefore, preferred by students who would be unable to attend lectures on a daily basis due to their other responsibilities and/or lack of resources. Yasmin (2013) cites how DL has been effective in reducing several barriers to traditional learning, namely inaccessibility due to geographical locations, previous subpar educational completion and financial restrictions. Since the advent of distance learning as an alternative means of formal education, there have been a number of significant transformations in not only the provision of education in distance education but also the learning experience by students. According to Van Antwerpen (2015), ODL presents learners with an opportunity to engage in an environment free of physical interaction. Distance learning presents a significant opportunity for the prospective student who seeks flexibility in education, however, it is not without its challenges. Pozdnyakova and Pozdnyak (2016) speculate that these challenges are predominantly related to the lack of corporeal co-presence between the student and lecturer or tutor. Croft et al. (2010) substantiates this perspective by reflecting on the absence of physical interaction, due to temporal separation, which may invoke feelings of isolation in the student. Croft et al. (2010) further elaborates that this lack of interaction lessens the value of the learning experience.

\subsection{Research Question and Objectives}

Over the years there has been an increase in the number of courses offered online as well as the number of students enrolled for these courses. However, distance learning students still face a number of challenges with the administrative and the learning processes throughout their studies. Distance learning institutions' lack of interaction has led to distance learners as having been characterized as having feelings of isolation (Zaborova \& Markova, 2016 cited in Markova et al., 2017). Mbatha (2013) recommends consistent communication and interaction, especially in the presentation of course material, in distance learning. Although learner support services exist in such institutions (face-to-face tutorials, video and satellite broadcasting, and counselling services), these services are not always effective in addressing such challenges. In view of the above, it is essential to both ascertain and identify these challenges, in order to proceed to examine possible apparatuses that can be employed in enhancing the ODL learning experience. This study will thus only focus on the learning experiences of ODL learning students and how immersive technologies can be used to address these challenges. Various technology tools have been employed in education, with the goal of enhancing and increasing the quality of the learning experience. In the modern world, learning institutions have looked to employ technology tools that will further stimulate active learner engagement with academic content. Immersive learning technology tools, (which involve the use of gaming, simulations and AR and VR) have largely been used in education in most recent years in order to provide immersive learning experiences.

This paper aims to answer the primary research question; How can open and distance learning be enhanced using virtual and augmented reality technologies?

Three research objectives have been outlined in order to answer the primary research question. The first objective is to investigate the challenges that are currently being experienced in distance learning. Second, to determine what ICT tools are currently being used to support distance learning. Third objective, to investigate how augmented and virtual reality is currently being used to enhance higher education. A systematic literature review will be employed to address these objectives.

The study builds on work that support the use of modern technologies in the enhancement of DL courses. In a study conducted by Mawn et al. (2011), the author states that the study is evidence that field- experiments can be incorporated in the DL science coursework. "Distance learning opportunities such as these can enable students to increase their science content knowledge while also developing scientific process skills, all while doing so on their own schedules and from varied locations (Mawn et al., 2011, p145).

\section{DESIGN AND METHODOLOGY}

This study made use of a qualitative research methodology through a systematic literature review. Qualitative data predominantly refers to data collection methods (eg. Interviews) or data analysis approaches that produce non-numerical data (Saunders et al., 2009). The study aims to comprehend the challenges experienced in distance learning while establishing the role that immersive technologies such as virtual reality can play in 
bridging these challenges.

\subsection{Data Collection}

A total amount of 40 papers were chosen for this paper. The Research papers were analyzed in this study included the following words "distance education", "immersive learning" "distance learning challenges", "practical modules distance learning", "distance learning experience", "distance learning South Africa", "distance learning technology", "virtual reality higher learning", "augmented reality higher learning". Various search engines were utilized to find these articles; Taylor and Francis, Science Direct, Researchgate and EBSCO Host were primarily made use of. Other articles were found on Google Scholar and IEEE and through journal articles that were under review. The selection of keywords was then followed by an inclusion and exclusion criteria. Okoloi and Schabram (2010) articulate that this stage of the search is centered on two categories of practical criteria: according to whether the research paper's content is relevant to the primary research question. Okoloi and Schabram (2010) emphasize the importance of this section as it is imperative that the researcher justify how the research can be considered as being extensive given the exclusion criteria. The first criteria were the language of the articles. This was specifically included as the authors mainly had access to English language articles. The time frame for selecting the articles ranging from 2000 to 2018 in order to compare the differing views of researchers throughout the years and additionally to ensure that the most relevant and recently updated data was used. Okoloi and Schabram (2010) substantiate this reasoning as they state that it is essential that the selection be broad enough so as to incorporate a satisfactory amount of articles that can adequately answer the primary research question. Conversely, the review needs to be practically manageable, taking into consideration the researcher's limitations of time, money, and personnel. Table 1 presents the inclusion and exclusion criteria of the paper.

Table 1. Inclusion and exclusion criteria for journal selection

\begin{tabular}{|c|c|c|}
\hline Criteria & Inclusion & Exclusion \\
\hline 1.Language of papers & $\begin{array}{l}\text { Articles must be written in } \\
\text { English }\end{array}$ & $\begin{array}{l}\text { Articles written in } \\
\text { other language except } \\
\text { English }\end{array}$ \\
\hline $\begin{array}{l}\text { 2. Time frame (date of } \\
\text { publication) }\end{array}$ & $\begin{array}{l}\text { Articles must be published } \\
\text { between } 2000 \text { to } 2018\end{array}$ & $\begin{array}{l}\text { Articles published } \\
\text { before } 2000\end{array}$ \\
\hline 3. Type of publication & $\begin{array}{l}\text { Peer reviewed journal articles, } \\
\text { conference papers or reports }\end{array}$ & $\begin{array}{l}\text { Books, magazines } \\
\text { and opinion pieces }\end{array}$ \\
\hline $\begin{array}{l}\text { 4.Phenomenon of interest: } \\
\text { Distance Education }\end{array}$ & $\begin{array}{l}\text { Higher education institutions } \\
\text { that offer distance education }\end{array}$ & $\begin{array}{l}\text { Traditional higher } \\
\text { education }\end{array}$ \\
\hline $\begin{array}{l}\text { 5. Phenomenon of interest: } \\
\text { Immersive learning }\end{array}$ & $\begin{array}{l}\text { Institutions where immersive } \\
\text { learning has been used }\end{array}$ & $\begin{array}{l}\text { Institutions that used } \\
\text { AR and VR but not } \\
\text { for the purpose of } \\
\text { learning. } \\
\text { (Businesses) }\end{array}$ \\
\hline $\begin{array}{l}\text { 6. Setting/ population: } \\
\text { distance learning }\end{array}$ & Distance learning students & Full-Time students \\
\hline $\begin{array}{l}\text { 7. Relevance to distance } \\
\text { education }\end{array}$ & $\begin{array}{l}\text { Articles are relevant to distance } \\
\text { learning experience }\end{array}$ & $\begin{array}{l}\text { Articles are } \\
\text { insignificant to the } \\
\text { study }\end{array}$ \\
\hline
\end{tabular}

\subsubsection{Data Extraction}

The extraction and analysis of data was guided by the research objectives that have been set out. The study utilized a thematic analysis in order to extract and analyses data. The use of a thematic analysis is advantageous as JBI (2014) states that a thematic synthesis allows the researcher to make inferences focused on common 
elements that address the research objectives. Table three below is an example of a data extraction and categorization table. Articles are numbered and categorized according to the relevant concepts discussed in the article. The category section of the table is related to the outlined objectives that each article may potentially assist in addressing. These outlined objectives were classified as distance learning challenges; distance learning technology tools, and immersive learning. Within the first and second objective, three themes were identified; psychological challenges, teaching style and interaction. These themes assisted in the extracting of relevant data in the articles, addressing the objectives of the study and essentially highlighting and validating the statement of the research problem. Additionally, through the review of articles, the findings revealed another theme "Towards immersive technology use in ODL" which highlights practical ODL courses. The third objective aimed to articulate how immersive learning has been utilized in higher education while highlighting the both the positive and negative aspects of its adoption. Initially, the themes were categorized as Immersive learning challenges and immersive learning advantages. Subsequently, through further scrutiny these themes were further dissected into areas of use, learning outcomes, learner engagement, and adoption challenges.

\section{SYSTEMATIC LITERATURE REVIEW THEMATIC DISCUSSION}

\subsection{Distance Learning}

\subsubsection{Psychological Challenges}

Distance learning institutions have a vast array of students that make use of a variation of learning styles. This poses a challenge in the provision of learning as distance learning tends to make use of the "one size fits all" method (Croft et al., 2010). For example, aural learners may be disadvantaged as they would most likely fair better in traditional lecture rooms, while visual learners are more likely to prefer making use of the internet. It is imperative to seek alternative methods of relating course material, at the risk of creating intellectual isolation in students (Croft, et al., 2010). Simpson (2013) supports this argument by stating how evidence indicates that distance learning educators focus on the distribution of course material as opposed to than the learning experience. Simpson (2013) further elaborates that this challenge can also be attributed to the unsatisfactory graduation rate in higher distance learning institutions, in comparison to traditional institutions. Advocates of DL maintain that distance learning can be as effective or may even surpass traditional learning (Markova, et al., 2017). Zaborova \& Markova (2016) critique DL, having noted that learners in virtual environments tend to exhibit feelings of confusion, isolation and frustration. Gravani (2015) details that DL students expressed their feelings regarding the learning experience as being: disappointing, filled with anxiety, constant tiredness, pressure, marginalization, and relegation. Koutsoupidou (2014) reports that the most significant drawback of DL is the psychological issues associated with the course for both the learner and the lecturer. Koutsoupidou (2014) further elaborates that isolation may become a restrictive factor in for learners' enthusiasm for the course and may even serve as justification for them dropping out.

\subsubsection{Distance Learning Instruction Tools}

Distance learning has become one of the most prevalent factors that have encouraged the frequent use of information and communication technologies (ICT) in institutions of higher education (Markova et al., 2017). Koutsoupidou (2015) states that digital tools are imperative with regards to the comprehension of a variation of open distance learning courses. Guri-Rosenblit (2009) supports this notion by detailing that Technological devices, from printed letters, radio, compact disc players, television and video to the modern internet-based learning, technology has always fashioned the construction of engagement between learners, educators and the academic content that is taught in ODL settings.

Online courses have improved promptly in higher institutions of learning with technology and the internet replacing the traditional face-to-face interaction. According to Rodrigues et al. (2014) distance learning is dependent on modern-day teaching practices which are comprised of technological resources that assist the facilitation of communication between lecturer and students. Numerous resources are currently available to assist the DL learner; university learning management systems, e-libraries, e-database, online- textbooks, video conferencing facilities, email and printed material (Markova et al., 2017). However, these resources are not available in all distance education institutions. Alternatively, in other institutions teaching and the provision of 
course material is carried out through the use of tutorial classes, e-learning, and audio course material. Markova et al. (2017) reports that DL lecturers often made use of online lectures, tests, exams, and course paper presentations but seldom made use of interactive training methods. Markova et al. (2017) further argue that in order to improve the quality of student knowledge in DL, it is imperative to enhance the level of instruction and to also seek new methods of educating as opposed to replicating traditional methods. Dede (2014) argues that the rapid growth of technology will have a considerable effect on Distance learning education. Martín-Gutiérrez et al. (2015) support this by reporting there has been a keen interest amongst educators, researchers, and pedagogues on utilizing new visualization methods to enhance current education frameworks. Modern technology that currently exhibits the most potential is virtual and augmented reality (AR).

\subsection{Immersive Learning}

\subsubsection{Areas of Use}

The evolution of the internet prompted a surge in the use of online teaching programs and the use of technology in education; these have reshaped the traditional education system. Technology tools such as AR, for example, make it possible to interlink real-world aspects by capturing them using a camera with multimedia factors for instance "text, images, video or three-dimensional models and animations." (Martín- Gutiérrez, et al., 2015). AR and VR present an opportunity to enhance the distance learning student experience. Additionally, it displays prospects of possibly assisting in the challenges experienced by the DL students. Herrington et al. (2007) reported that a sizeable amount of various institutions was incorporating simulations into their educational environment. Realistic simulations were commonly used in education settings that are deemed to have "high stakes", these sectors comprise of space training, medical education, and piloting. Rizov \& Rizova (2015) substantiates this as the author asserts that is possible for augmented reality to be implemented and be beneficial to various disciplines, such as medicine, education, and architecture. "Alien Contact!" is a scenario-based simulation, was employed to enhance mathematical thinking capabilities (Dunleavy et al., 2009; Mitchell, 2011). Gamification and role-play-based AR has been implemented to increase motivation and a sense of realisticness in medical science (Rosenbaum et al., 2007). The aforementioned is an indication of the potential that immersive learning has in the enhancing of the ODL learning experience as Mawn et al. (2011) had emphasized the necessity to not only enhance theoretical knowledge but to also hone the learning of practical skills. The use of AR in education may be relatively new, however, there are several AR applications that may be utilized in various learning contexts.

VR similarly to AR has been employed in various educational contexts. A virtual exercise was implemented in a microbiology course, Flint and Stewart (2010) deduced that learners not only enjoyed the virtual exercise, but it also met the objectives, was relatively inexpensive for the university, and its speed was 10 times than that of a traditional laboratory exercise (Flint and Stewart 2010). There was, however, a large emphasis on student's prior knowledge of laboratory techniques, therefore Flint and Stewart (2010) do not recommend the use of virtual laboratories in isolation as a replacement for traditional laboratories. Additionally, several researchers have studied the use of virtual laboratories as a supplement. Dalgarno et al. (2009) intended on familiarizing chemistry learners, who were studying from a distance, by utilizing a virtual environment. Dalgarno et al. (2009) reported that students stated that the virtual laboratory would be an effective tool to assist with the advancement of their familiarity with the traditional chemistry laboratory. Koretsky et al. (2011) provided a different application of supplementary virtual environments. There was no physical laboratory counterpart for the virtual exercise in which Koretsky et al. (2011) presented engineering learners with laboratory settings and practices that depicted industry more realistically than the traditional laboratory could. Koretsky et al. (2011 p.567) concluded that 'virtual laboratories can facilitate a broader experience for students'. Koretsky et al. (2011) further elaborated that the various sorts of experiments (physical vs. virtual) direct learners' consciousness of their learning towards various factors, for example; "laboratory procedures in traditional laboratories versus critical thinking and higher-order cognition in virtual laboratories".

\subsubsection{Learning Outcomes}

One of the aforementioned challenges experienced by distance learners is the feeling of isolation. Rizov \& Rizova (2015) conducted research on the use of augmented reality as a teaching tool; positive results were reported in the initial implementation of the application of augmented reality as an instruction tool. This 
indication may suggest a possible solution to the feeling of isolation experienced by students. Rizov \& Rizova, (2015) states that making use of tools that depict the modern world is beneficial as it assists in maintaining learner's interests. Herrington et al. (2007, p13) reports that "the task is the crucial component of immersion and engagement in higher-order learning." When suitable technologies are utilized as cognitive instruments to find solutions to challenging problems, the learning obligation is shifted to the student as opposed to the engineer of the virtual world. Herrington et al. (2007) thus concludes that the onus is on the student to determine the method on how to complete the task. Taking into account that learning method is deemed to be reflective (Herrington et al., 2007), the use of virtual worlds may prove to be beneficial in addressing the DL challenge highlighted by Simpson (2013) of educators focusing on the distribution of content as opposed to the learning experience. However, Lee et al. (2017) reports that when making use of virtual reality primarily for the delivery of content, only a marginal benefit exists in terms of content absorption. Lee et al. (2017) further details that despite this, it should not be assumed that virtual reality is ineffective. Martín-Gutiérrez et al. (2015) conducted a study that focused on the following teaching contexts; the utilization of electrical apparatus in the laboratory, analyzing and interpretation of illustrations for reviewing installations, and autonomous learning of course work. Motivated students were reported to have had a positive academic performance. The positive outcomes and feedback from students from the use of new technology correlates with Leszczyński et al. (2017) study of an emergency medicine DL course. Leszczyński et al. (2017) found that students are enthusiastic about the use of modern methods of education, value the substantive quality and innovation presented by these new materials and are quick to adjust to new technologies. The use of immersive technology in education has been found to enrich the skills that students are expected to obtain. Patiar et al. (2017) study asserts that the VFT enabled learners to improve both their cognitive and attitudinal skills too. Moreover, the VFT tool aids learners' personal development and presents opportunities for independent knowledge seekers by modifying learners' experience of reality. Webster (2016) examined a US Army traditional lecture an immersive virtual reality-based multimedia teaching, in terms of attaining declarative knowledge. The VR instruction tool was found to offer high time-compressed training, it was able to be customized to the students' knowledge level, can permit numerous repetitions that are needed in order to increase mastery (Webster, 2016). Immersive technologies can be seen as an appropriate measure to address a DL experience challenge detailed by Croft et al. (2010). The challenge is the use of a "one size fits all" teaching approach made use by educators, that in turn, impacts influence the students' ability to assimilate information (Croft et al., 2010). Rizov \& Rizova, (2015) corroborated this as the authors reported that educators expressed that AR succeeded in decreasing the amount of time spent attempting to assist students in assimilating information.

\subsubsection{Learner Engagement}

Learner engagement is essential in the provision of the academic content, therefore students who take in interest in the course material are more likely to find value in the learning process. Rizov \& Rizova (2015) conducted a test on students based on their knowledge of engineering graphics. However, Rizov \& Rizova, (2015) reports that after educators employed augmented reality in assisting with the displaying of space objects, positive growth in the results could be viewed. Furthermore, Rizov \& Rizova (2015) noted a benefit that physical interaction between students and the application contributed further to the learning of various geometric shapes in the cosmos. Contrastingly a study conducted by Dyrberg et al. (2017 p.358) aimed to examine "a pilot study on student attitude, motivation and self-efficacy when using the virtual laboratory programme Labster." Dyrberg et al. (2017) details that students found less value in interacting in the virtual laboratory in comparison to participating in a traditional laboratory. Dyrberg et al. (2017) reports that the cases appeared to be less engaging, motivating and useful in comparison to doing traditional laboratory work. This also contradicts Flint and Stewart (2010) whose study found that learners in a microbiology course experienced increased enjoyment with a virtual laboratory as opposed to a traditional laboratory. The results by Dyrberg et al. (2017) do, however, support the findings by Dalgarno et al. (2009) who reported that virtual laboratories can be employed when familiarizing students with virtual laboratory before the official sessions. Dyrberg et al. (2017) reported that learners had notably greater confidence when conducting laboratory experiments.

\subsubsection{Adoption Challenges}

Researchers have varying opinions on the feasibility of successfully implementing immersive technologies in education. Although there are several studies that have reported the successful use of immersive technologies, there are researchers who still remain hesitant regarding immersive learning. Saleem et al. (2017) highlighted 
a significant issue that the prolonged use of these devices (immersive and wearable devices) may cause health issues. Saleem et al. (2017) indicates that the health issues are related to skin allergies, rashes, etc. additionally the weight of the device is also a significant concern as to whether the device can be easily carried and be mobile. Herrington et al. (2007) state that provision immersive learning technology simulations is exceedingly expensive, thus resulting in their use being limited. Conversely, Martín-Gutiérrez et al. (2015) stated augmented reality is a relatively inexpensive technology that assists in delivering course work in a more appealing manner to students. In a recent study, Saleem et al. (2017) reported that IDC (a firm providing global market intelligence) estimated in 2014 that the need for immersive and wearable devices would increase up to 112 million units by 2018 , with Google glasses being the most expensive device ranging around $1500 \$$. Saleem et al. (2017) note that in certain countries this may be viewed as an affordable price, however, the rest of the world may not be on par with these prices, particularly in developing particularly developing countries. Despite the various benefits, the cost factor may significantly impede the adoption of AR and VR in ODL in a developing country such as South Africa.

Ellaway et al. (2003) referred to access as a possible limitation to the application of virtual environments in the classroom. Ellaway et al. (2003) expounds on this argument stating that even though the internet has become predominant in all aspects of modern-day society, there are noteworthy setbacks that may affect the potential users when accessing the system, for example, the lack of networked computing equipment. Ellaway et al. (2003) highlights staff development as another possible hindrance to the application of a virtual environment in education. In order to facilitate system development, the staff will require technical training on the system. Saleem et al. (2017) further elaborates on access in the context of connectivity as the study reports that the devices require a continuous data update which involves the use of an Internet connection. This poses a challenge as developing and even some developed countries are unable to provide all of its citizens with adequate Internet. Saleem et al. (2017, p692) reports that in 2013 "a mere $42 \%$ of the global population had internet access. When narrowed down to the continents $13 \%$ of the population in North America had no access, 28\% in Australia, 30\% in Europe, $48 \%$ in Latin America, 52\% in the Middle East, 64\% in Asia, and 74\% in Africa still did not have access to the Internet."

Taking into account these limitations researchermarkovs have still found the use of immersive learning in higher education learning, particularly in courses that require practical engagement, as significantly beneficial in improving the learning experience (Baukal, 2010; Güven 2014; Mawn et al., 2011). Ellaway et al. (2003) however, reported that although virtual learning environments are able to provide exceptional support for the complex, dispersed and integrated practices of medical education, investment, community commitment and stakeholder buy-in will remain the most critical hindrance to implementation. Without these factors, VLEs will be inclined to linger on the periphery, to only be utilized by enthusiasts and early adopters only. Porter et al. (2016) cited the adoption innovation patterns that may possibly impede or facilitate the implementation of an immersive environment in higher education. Porter et al. (2016) reported that innovators and early adopters could be influenced through the provision of infrastructure and assistance, and in addition to clarifying the rationale for implementing blended learning. The early majority was reported to be influenced by evaluation data. The conclusion of the report on the late majority suggested that adequate training and support in a safe environment would result in their support.

\section{DISCUSSION}

Cornelius et al. (2008) stated that in the modern world, it would be rare to find a "fulltime student". Instructors were aware of the unavoidable need to meet the modern student's needs; students who work part-time, study from the convenience of their house, and or in their workplace, residence halls, and also those who fall in the gap of being unable to access computing resources. This description supported the statement by Rodrigues et al. (2014) detailing why individuals became distance learners. Despite the advantages presented by distance learners, the distance learners were confronted with numerous challenges that affected their learning experience (Markova et al., 2017; Gravani 2015; Koutsoupidou, 2014) these challenges included psychological challenges; feelings of isolation, anxiety marginalization, a lack of efficient in-depth content delivery, physical interaction when having a dialogue, rigid course materials and learning methods. Although there were several technology tools such as; e-libraries, e-database, online-textbooks, video conferencing and email (Markova et al., 2017), learners were still found to experience these challenges. 
Cornelius et al. (2008) affirmed that a virtual environment presented an opportunity for educators to meet the needs of the modern student while, at the same time, affording students with several, not all, of the components of a real-life environmental experience. Although a virtual environment may not have been able to compare to a real visit to space, a national park, an aquarium, the amazon or a historical site, it did offer

students an opportunity to obtain a realistic perspective with reference to the module that they are learning. AR and VR have exhibited several benefits that may assist in enhancing the distance learning experience. The majority of the studies (Rizov \& Rizova ,2015; Herrington et al., 2007; Martín-Gutiérrez et al., 2015; Patiar et al., 2017; Webster, 2016) indicated that the adoption of immersive learning in higher education fostered an increase in learner engagement, a better assimilation of course content and a better development of practical skills. Bower et al. (2014) argued that the use of virtual reality may be of more use to educational courses that rely on the development of practical skills as opposed to modules that were based on content absorption. Studies which focused on courses in ODL that required the development of practical skills (Baukal, 2010; Güven 2014; Mawn et al., 2011), substantiated the argument by Bower et al. (2014).

The most significant factors that may have potentially impeded the adoption and application of immersive technology in ODL are funding, health factors and accessibility or a lack thereof, in both developed and developing countries. However, recent advancements in mobile computing and operational performance had brought about an increased allocation of resources to the development of mobile AR systems (Bower et al., 2014; Johnson et al., 2010). Augmented reality had, therefore, become more commonly available to the general public, in comparison to previously, when it had been exclusively located in high-end laboratory research and industry. One of the challenges faced by distance learning students is the feeling of isolation, which stems from a lack of interaction and a "blanket" teaching style. Bower et al. (2014) maintained that the more intelligent and advanced augmented reality became, it would possess the ability to alert lecturers and tutors to a pupil's learning needs, possible behavioural concerns, and recommend an applicable course of action in real-time.

It is essential to note that the studies that made use of AR and VR in higher education did not implement immersive tools in isolation. Singh et al. (2002) maintained that the augmentation of traditional practices in higher education learning must be viewed as a tool to enrich teaching and learning and not as a complete replacement of traditional learning. Cornelius et al. (2008) substantiated this notion stating that virtual environments should only be considered as complements or supplements to the existing teaching methods and not as a replacement. This statement also satisfied the main objective of this study which is to answer the primary research question; "How can open and distance learning be enhanced using virtual and augmented reality technologies?" Additionally, Ellaway et al. (2003) reported that when aiming to take full advantage of the educational learning outcomes of immersive learning, it would be essential that the virtual learning environment (VLE) is aligned with the practices and outcomes of the course. The course must inform the VLEs and VLEs need to be modifiable to meet course outcomes and not to modify them to meet VLE limitations.

\section{CONCLUSION}

This study investigated how immersive technologies (AR and VR), may be used to enhance the distance learning experience. The study presented a mini systematic literature review in which a thematic discussion was implemented. The themes for the thematic discussion were informed by the three research objectives which were (1) to investigate the challenges that are currently being experienced in distance learning (2) to determine what ICT tools are currently being used to support distance learning (3), to investigate how AR and VR is currently being used to enhance higher education. The aims were achieved through a selection of journal articles that met the inclusion and exclusion criteria. Literature findings revealed that the most prevalent challenges amongst ODL students were psychological challenges; feelings of isolation, anxiety marginalization, a lack of efficient in depth content delivery, rigid course materials and learning methods. Learners still experienced challenges with the ODL learning experience regardless of having had technology tools that are currently being employed in ODL (e-libraries, e-database, online-textbooks, and video conferencing) to improve the learning experience. Additionally, the literature revealed that there has been several uses of AR and VR in higher education, however, it is more beneficial when employed in courses that require the development of practical skills. Various authors noted that although immersive learning presents various advantages in the learning environment, $A R$ and VR should not be used as a replacement for traditional teaching but rather as a supplement. AR and VR was found to have contributed to learner engagement and 
enhanced learning outcomes but there are still several significant challenges that may still impede the adoption of immersive learning in ODL. The outlined aims of the study were achieved however, in order to fully answer the primary research question, future studies should be focused on how to address the adoption challenges of AR and VR, especially in developing countries. Furthermore, future studies should additionally focus on providing a framework for the adoption of AR and VR in ODL.

\section{REFERENCES}

Al-Arimi, A.M.A.K., 2014. Distance learning. Procedia-Social and Behavioral Sciences, 152, pp.82-88. Baukal, C.E., 2010.

Behavioral Sciences, 182, pp.685-691.

Bower, M., Howe, C., McCredie, N., Robinson, A. and Grover, D., 2014. Augmented Reality in education-cases, places and potentials. Educational Media International, 51(1), pp.1-15.

Continuing engineering education through distance learning. European Journal of Engineering Education, 35(2), pp.225-233.

Cornelius, S., Medyckyj-Scott, D., Forrest, D., Williams, A. and Mackaness, W., 2008. The virtual placement: an alternative to the traditional work placement in the geographical sciences? Journal of Geography in Higher Education, 32(2), pp.287-302.

Craft, N., Dalton, A. and Grant, M. (2010). Overcoming Isolation in Distance Learning: Building a Learning Community through Time and Space. Journal for Education in the Built Environment, 5(1), pp.27-64.

Dalgarno, B., Bishop, A.G., Adlong, W. and Bedgood Jr, D.R., 2009. Effectiveness of a virtual laboratory as a preparatory resource for distance education chemistry students. Computers \& Education, 53(3), pp.853-865.

Dede, CJ (2014). The Evolution of Distance Learning, Journal of Research on Computing in Education, 22:3, 247-264, DOI: $10.1080 / 08886504.1990 .10781919$

Dunleavy, M., Dede, C. and Mitchell, R., 2009. Affordances and limitations of immersive participatory Augmented reality simulations for teaching and learning. Journal of science Education and Technology, 18(1), pp.7-22.

Dyrberg, N.R., Treusch, A.H. and Wiegand, C., 2017. Virtual laboratories in science education: students' motivation and experiences in two tertiary biology courses. Journal of Biological Education, 51(4), pp.358-374.

Ellaway, R., Dewhurst, D. and Cumming, A., 2003. Managing and supporting medical education with a virtual learning environment: The Edinburgh Electronic Medical Curriculum. Medical Teacher, 25(4), pp.372- 380.

Flint, S. and Stewart, T., 2010. Food microbiology—design and testing of a virtual laboratory exercise. Journal of Food Science Education, 9(4), pp.84-89.

Gravani, M.N., 2015. Adult learning in a distance education context: Theoretical and methodological challenges. International Journal of Lifelong Education, 34(2), pp.172-193.

Guri-Rosenblit, S., 2009. Distance education in the digital age: Common misconceptions and challenging tasks. Journal of distance education, 23(2), pp.105-122.

Güven, M., 2014. Distance learning as an effective tool for medical interpreting training in Turkey. Open Learning: The Journal of Open, Distance and e-Learning, 29(2), pp.116-130. Ham, V. and Davey, R., 2005. Our first time: Two higher education tutors reflect on becoming a 'virtual teacher'. Innovations in Education and Teaching International, 42(3), pp.257-264.

Herrington, J., Reeves, T.C. and Oliver, R., 2007. Immersive learning technologies: Realism and online authentic learning. Journal of Computing in Higher Education, 19(1), pp.80-99.

Johnson, L., Smith, R., Levine, A., \& Haywood, K. (2010). The 2010 Horizon Report: Australia - New Zealand Edition. Austin, Texas: T. N. M. Consortium.

Koretsky, M., Kelly, C. and Gummer, E., 2011. Student perceptions of learning in the laboratory: Comparison of industrially situated virtual laboratories to capstone physical laboratories. Journal of Engineering Education, 100(3), pp.540-573.

Koutsoupidou, T., 2014. Online distance learning and music training: benefits, drawbacks and challenges. Open Learning:

Lee, S.H., Sergueeva, K., Catangui, M. and Kandaurova, M., 2017. Assessing Google Cardboard virtual reality as a content delivery system in business classrooms. Journal of Education for Business, 92(4), pp.153-160.

Leszczyński, P., Charuta, A., Gotlib, J., Kołodziejczak, B., Roszak, M. and Zacharuk, T., 2017. Distance Learning Methods in Continuing Education of Paramedics. Studies in Logic, Grammar and Rhetoric, 51(1), pp.53-70.

Letseka, M. and Pitsoe, V., 2014. The challenges and prospects of access to higher education at UNISA. Studies in Higher Education, 39(10), pp.1942-1954. 
Markova, T., Glazkova, I. and Zaborova, E., 2017. Quality issues of online distance learning. Procedia-Social and

Martín-Gutiérrez, J., Fabiani, P., Benesova, W., Meneses, M.D. and Mora, C.E., 2015. Augmented reality to promote collaborative and autonomous learning in higher education. Computers in Human Behavior, 51, pp.752-761.

Mawn, M.V., Carrico, P., Charuk, K., Stote, K.S. and Lawrence, B., 2011. Hands-on and online: scientific explorations through distance learning. Open Learning, 26(2), pp.135-146.

Mitchell, R., 2011.Alien Contact!: Exploring teacher implementation of an augmented reality curricular unit. Journal of Computers in Mathematics and Science Teaching, 30(3), pp.271-302.

Mounton, J., 2001. How to succeed in your masters and doctoral studies. Van Schaik. p. 166

Mouton, J. and Babbie, E., 2004. The practice of social research. Cape Town: Wadsworth. p. 76 \& p. 84

Patiar, A., Ma, E., Kensbock, S. and Cox, R., 2017. Students' perceptions of quality and satisfaction with virtual field trips of hotels. Journal of Hospitality and Tourism Management, 31, pp.134-141.

Porter, W.W., Graham, C.R., Bodily, R.G. and Sandberg, D.S., 2016. A qualitative analysis of institutional drivers and barriers to blended learning adoption in higher education. The internet and Higher education, 28, pp.17-27.

Pozdnyakova, O. and Pozdnyakov, A., 2017. Adult Students' Problems in the Distance Learning. Procedia Engineering, 178, pp.243-248.

Rizov, D. and Rizova, D. (2015). Augmented reality as a teaching tool in higher education. International Journal of Cognitive Research in Science, Engineering and Education, 3(1), pp.7-16.

Rodrigues, S.J., Affonso, S.A., Quinelato, E. and Montiel, J.M., 2014. Distance learning in undergraduate education: the challenges of building a collaborative environment. Procedia-Social and Behavioral Sciences, 116, pp.3499-3501. Rosenbaum, E., Klopfer, E. and Perry, J., 2007. On location learning: Authentic applied science with networked augmented realities. Journal of Science Education and Technology, 16(1), pp.31-45.

Saunders, M., Lewis, P. and Thornhill, A., 2009. Understanding research philosophies and approaches. Research methods for business students, 4, pp.106-135.

Siddaway, A. (2014). What is a Systematic Literature Review and How do I do one? |p. 11/13. [online] cybermanual.com. Available at: http://www.cybermanual.com/what-is-a-systematic-literature-review- and-how-do-i-doone.html?page=11 [Accessed 20 May 2018].

Simpson, M. and Anderson, B., 2012. History and heritage in open, flexible and distance education. Journal of Open, Flexible, and Distance Learning, 16(2), pp.1-10.

Simpson, O. (2013). Student retention in distance education: are we failing our students? Open Learning: The Journal of Open, Distance and e-Learning, 28(2), pp.105-119.

Singh, G., O'Donoghue, J. and Betts, C., 2002. A UK study into the potential effects of virtual education: does online learning spell an end for on-campus learning?. Behaviour \& Information Technology, 21(3), pp.223-229.

The Journal of Open, Distance and e-Learning, 29(3), pp.243-255. 